\title{
Hemimedullary Syndrome with Ipsilateral Sensorimotor Deficits
}

\author{
Hee-Young Shin ${ }^{\mathrm{a}}$ Byoung-Joon Kim ${ }^{\mathrm{a}}$ Yun-Hee Kim ${ }^{\mathrm{b}}$ Sung Tae Kim ${ }^{\mathrm{c}}$ Chin-Sang Chung ${ }^{\mathrm{a}}$ \\ Kwang Ho Lee ${ }^{a}$ Gyeong-Moon Kim ${ }^{a}$ \\ Departments of a Neurology, ${ }^{\mathrm{b}}$ Physical Medicine and Rehabilitation, and ${ }^{\mathrm{c}}$ Radiology, Samsung Medical Center, \\ Sungkyunkwan University School of Medicine, Seoul, Korea
}

Dear Sir,

Hemimedullary syndrome has been introduced as Babinski-Nageotte syndrome or Reinhold syndrome with ischemic lesion in unilateral lateral and medial medulla oblongata [1-3]. The identity of hemimedullary stroke has remained controversial because both medial and lateral medullary infarctions rarely occur simultaneously and vascular supplies of the medial and lateral medulla usually differ $[4,5]$. Rarely, the lower medullary lesion caused the symptoms of ipsilateral hemiparesis with sensory loss [6, 7]. Here we describe a patient with hemimedullary syndrome in conjunction with ipsilateral hemiparesis and sensory loss caused by ipsilateral, vertebral artery dissection. The ipsilateral motor weakness was evaluated by diffusion tensor imaging (DTI) and transcranial magnetic stimulation (TMS) study.

\section{Case Report}

A 50-year-old man with a 5-year history of hypertension and diabetes was admitted to our hospital on March 26, 2005, because of vertigo with nausea, vomiting and rightsided weakness. His symptoms had begun 2 days prior to admission. However, he did not experience headache, neck pain, or visual symptoms.
On admission, he complained of rightsided weakness, right facial palsy, dysarthria, and dysphagia. His blood pressure was $167 / 104 \mathrm{~mm} \mathrm{Hg}$, pulse rate was regular at $78 / \mathrm{min}$ and body temperature was $36.7^{\circ} \mathrm{C}$. Physical examination showed no abnormality in the chest or abdomen. His mental state was alert. Neurologic examination demonstrated right upper, motor neuron-type facial palsy with dysarthria, dysphagia, and paralysis of the right tongue and palate. His right eye had left beating and upbeat nystagmus in horizontal and vertical planes, and he also showed right-sided head tilt, ocular tilt, lateropulsion and hypometric saccade to the right. In addition, he showed right hemiparesis (arm: MRC grade IV, leg: III), right-sided hyperalgesia and decreased perception of vibration sense, as well as increased deep tendon reflex in the right arm and leg. His right limbs were ataxic and he could not stand without assistance.

Brain magnetic resonance imaging with angiography was performed. Diffusionweighted imaging revealed a hyperintense lesion in the right dorsolateral medulla oblongata and FLAIR imaging showed a hyperintense lesion in the right medial and lateral medulla oblongata with extension of the lesion in the cervicomedullary junction (fig. 1A-C). Magnetic resonance angiography did not delineate the right vertebral artery and luminal widening of the left vertebral artery, which suggested dissection of the vertebral artery (fig. 1D). These neuroradiological studies did not document any parenchymal or vascular lesions in the anterior circulation. Blood test showed no specific abnormality in the thrombotic profile. Echocardiography with contrast echo study showed a $0.13-\mathrm{cm}$-sized, patent foramen ovale with right-to-left shunt. We evaluated the pyramidal motor pathway by DTI and TMS study. DTI showed a decreased mean fractional anisotropy value in the right lower medullar region (right, $0.54 \pm 0.08$; left, $0.74 \pm 0.09$ ) as well as a decreased density of the right-sided pyramidal motor fibers (fig. 1E). TMS study suggested delayed conduction velocity in the right postdecussational corticospinal pathway (table 1).

Anticoagulation therapy had been discontinued because of massive duodenal ulcer bleeding. One month after admission, neurologic examination showed mild neurological deficits, which included right monoparesis in the leg (MRC grade IV), right facial palsy with tongue deviation to the right, and right-sided limb ataxia. Sensory deficits in his right side and the degree of nystagmus were markedly diminished.

\section{KARGER}

Fax +4161306 1234 E-Mail karger@karger.ch www.karger.com
(C) 2006 S. Karger AG, Basel 0014-3022/06/0551-0046\$23.50/0

Accessible online at:

www.karger.com/ene
Gyeong-Moon Kim, MD

Department of Neurology, Samsung Medical Center

Sungkyunkwan University School of Medicine

50 Ilwon-Dong, Kangnam-Ku, Seoul, 135-710 (Korea)

Tel. +82 23410 3598, Fax +82 23410 0052, E-Mail kimgm@smc.samsung.co.kr 


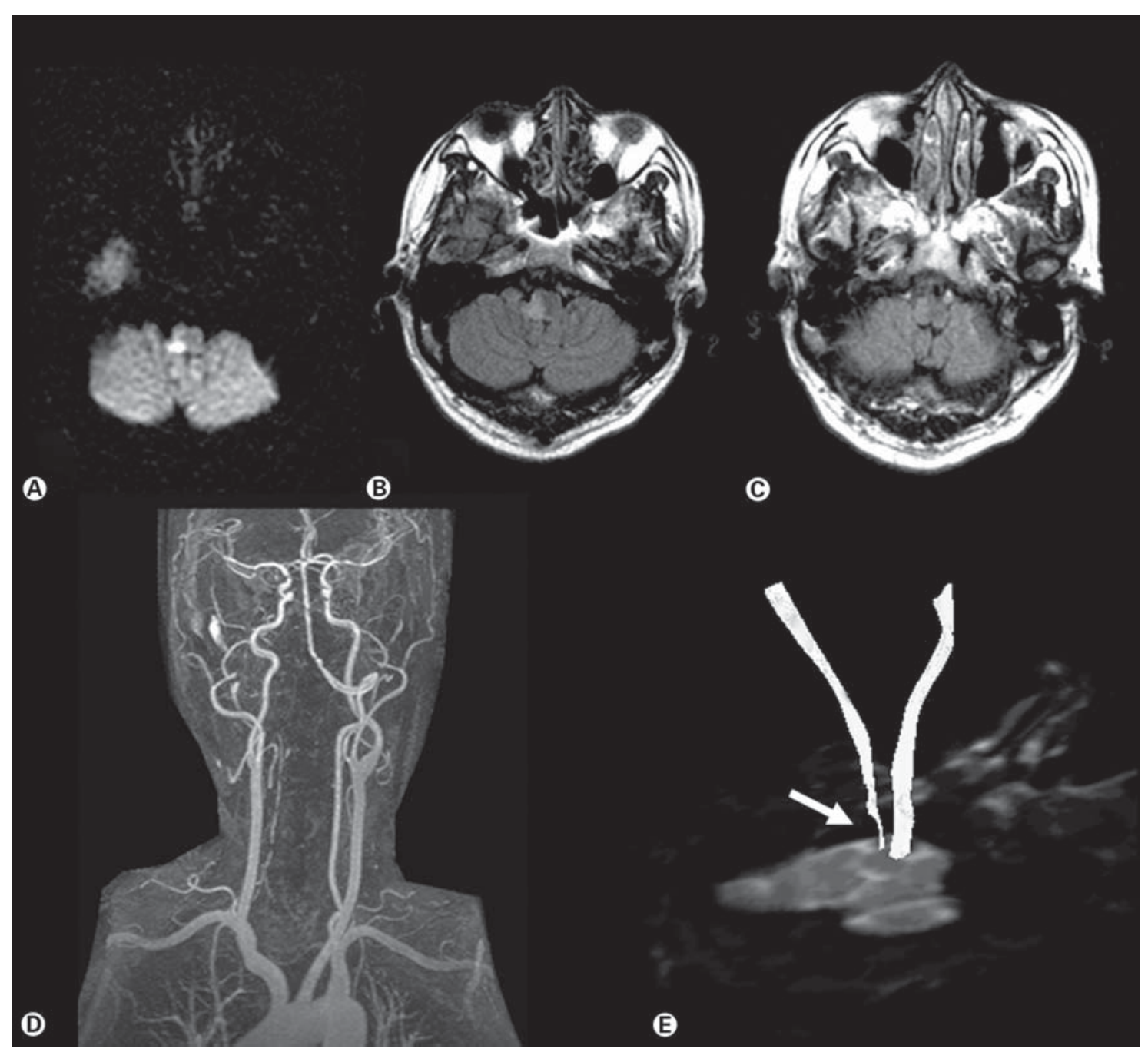

Fig. 1. Brain magnetic resonance imaging and angiography performed 3 days after symptom onset. A Diffusionweighted imaging shows a hyperintense lesion in the right dorsolateral medulla. B FLAIR magnetic resonance imaging demonstrates hyperintensity in the right medial and lateral medullar oblongata. C High signal intensity in the right hemimedullary area extended to the cervicomedullary junction in FLAIR image. D Magnetic resonance angiography shows multiple narrowings in the course of the right vertebral artery and luminal widening of the right vertebral artery. E Diffusion tensor tractography shows decreased fiber density in the right pyramidal tract at the medullary level (fractional anisotropy value: right, $0.54 \pm 0.08$; left, $0.74 \pm 0.09$ ).

\section{Discussion}

This is the first case report of hemimedullary infarction with ipsilateral hemiparesis documented by anatomical and functional studies. Our patient presented right hemiparesis due to right medial medullary involvement, which was an ipsilateral, postdecussational, pyramidal tract lesion. The condition was documented by decreased fiber density in the right postdecussated motor pathway on DTI study and delayed cortical motor conduction latency recorded from the tibialis anterior muscle in the right postdecussated portion on TMS study [8]. The more profound leg weakness could be explained by the lateral involvement of the pyramidal tract at the medullary level on 3-dimensional tractography. These anatomical and functional studies revealed right medial medullary involvement, and our patient also showed right paralysis of the tongue and palate, as well as decreased vibratory sense. In addition to clinical findings of medial medullary involvement, lateral medullary involvement was also present, as suggested by the patient's ocular findings, hyperalgesia to pinprick, hiccup, and right-sided ataxia. Grossly, he showed right-sided head tilt, and ophthalmoscopic examination revealed right upward deviation $\left(17^{\circ}\right)$ of the right eye visual axis. The nystagmus was composed of left beating and upbeat in vertical and horizontal planes, 
Table 1. Results of transcranial magnetic stimulation

\begin{tabular}{|c|c|c|c|c|c|c|}
\hline \multirow[t]{3}{*}{ Evoked site } & \multicolumn{6}{|c|}{ Recording site } \\
\hline & \multicolumn{3}{|c|}{ right tibialis anterior muscle } & \multicolumn{3}{|c|}{ left tibialis anterior muscle } \\
\hline & $\begin{array}{l}\text { latency } \\
\mathrm{ms}\end{array}$ & $\begin{array}{l}\text { amplitude } \\
\mathrm{mV}\end{array}$ & CML-F & $\begin{array}{l}\text { latency } \\
\mathrm{ms}\end{array}$ & $\begin{array}{l}\text { amplitude } \\
\mathrm{mV}\end{array}$ & CML-F \\
\hline Right motor cortex & 38.0 & 0.20 & 16.9 & 30.8 & 1.98 & 7.8 \\
\hline Left motor cortex & 39.0 & 0.25 & 14.6 & 35.3 & 0.15 & 11.2 \\
\hline
\end{tabular}

The right-sided, postdecussated portion showed delayed conduction with increased CML-F compared with the left tibialis anterior recording site.

$\mathrm{CML}-\mathrm{F}=$ cortical latency $-(\mathrm{M}$ latency $+\mathrm{F}$ latency -1$) / 2$; normal range $<13.4$. along with the presence of right lateropulsion and ipsilateral hypometric saccade, which was consistent with lateral medullary involvement [9]. The upbeat nystagmus might be explained by dorsomedial extension of the ischemic lesion to the nucleus intercalatus [10]. Ipsilateral sensory symptoms in the limb and body are an uncommon but distinct variant caused by caudal lesions extending dorsomedially that probably involve the ipsilateral dorsal column or decussating lemniscal fibers [11]. Our patient showed ipsilateral sensory deficits caused by lesion extended dorsomedially in the cervicomedullary junction. Also, magnetic resonance angiography showed multiple tubular stenoses with adjacent fusiform dilatation of the right vertebral artery and segmental widening with septum in the left vertebral artery, which suggested arterial dissection of both vertebral arteries [12]. Unlike previously reported cases of hemimedullary syndrome like Babinski-Nageotte syndrome or Reinhold syndrome, our patient showed ip- silateral sensorimotor deficits with medial and lateral medullary lesion extended to the cervicomedullary junction, which was caused by extensive ischemic insult due to vertebral artery dissection.

\section{References}

1 Mossuto-Agatiello L, Kniahynicki C: The hemimedullary syndrome: case report and review of the literature. J Neurol 1990;237:208212.

2 Krasnianski M, Neudecker S, Schluter A, Zierz S: Babinski-Nageotte's syndrome and hemimedullary (Reinhold's) syndrome are clinically and morphologically distinct conditions. J Neurol 2003;250:938-942.

3 Babinski J, Nageotte J: Hémiasynergie, latéropulsion et myosis bulbaires avec hémianesthésie et hémiplégie croisées. Rev Neurol (Paris) $1902 ; 10: 358-365$.

4 Nakane H, Okada Y, Sadoshima S, Fujisjima M: Babinski-Nageotte syndrome on magnetic resonance imaging. Stroke 1991;9:595-598.

5 Gan R, Noronha A: The medullary vascular syndromes revisited. J Neurol 1995;242:195202.
6 Tada M, Tada M, Ishiguro H, Hirota K: Babinski-Nageotte syndrome with ipsilateral hemiparesis. Arch Neurol 2005;62:676-677.

7 Dhamoon SK, Iqbal J, Collins GH: Ipsilateral hemiplegia and the Wallenberg syndrome. Arch Neurol 1984;41:179-180.

8 Kim YH, Jang SH, Byun WM, Han BS, Lee $\mathrm{KH}$, Ahn SH: Ipsilateral motor pathway confirmed by combined brain mapping of a patient with hemiparetic stroke: a case report. Arch Phys Med Rehabil 2004;85:1351-1353.

9 Tilikete C, Hermier M, Pelisson D, Vighetto A: Saccadic lateropulsion and upbeat nystagmus: disorders of caudal medulla. Ann Neurol 2002;52:658-662.

10 Jassen JC, Larner AJ, Morris H, Bronstein AM, Farmer SF: Upbeat nystagmus: clinicoanatomical correlation. J Neurol Neurosurg Psychiatry 1998;65:380-381.

11 Kim JS: Sensory symptoms in ipsilateral limbs/ body due to lateral medullary infarction. Neurology 2001;57:1230-1234.

12 Irie F, Toyoda K, Hagiwara N, Fujimoto S, Okada Y: Babinski-Nageotte syndrome due to vertebral artery dissection. Intern Med 2003; 42:871-874. 